

\title{
Fundamentos teórico-epistemológicos da Teoria Histórico-Cultural: implicações para a psicologia do desenvolvimento infantil
}

\author{
Theoretical-epistemological fundamentals of Cultural-Historical Theory: \\ Implications for child development psychology
}

\author{
Sandra Adriana Neves Nunes ${ }^{[a]}$, Marcos Gimenes Fernandes ${ }^{[b]}$, Arsenio José Carmona Gutierrez ${ }^{[c]}$
}

\footnotetext{
${ }^{[a]}$ Doutora em Psicologia , Professora Adjunta da Universidade Federal do Sul da Bahia (UFSB) e-mail: psandranunes7@hotmail.com

${ }^{[b]}$ Doutor em Educação Física, professor do Departamento de Ciências da Saúde da Universidade Estadual de Santa Cruz (UESC), Ilhéus, BA - Brasil, e-mail: gimenes@uesc.br

${ }^{[c]}$ Doutor em Educação, professor do Departamento de Ciências da Educação da Universidade Estadual de Santa Cruz (UESC), Ilhéus, BA - Brasil, e-mail: arseniocarmona@yahoo.es
}

Recebido: 14/02/2012 Received: 02/14/2012

Aprovado: 11/06/2012 Approved: 06/11/2012

\begin{abstract}
Resumo
As contribuições de Vygotsky para a pesquisa em psicologia parecem inegáveis na atualidade, mas permaneceram por algum tempo silenciadas. As razões para que continuem despertando o interesse de pesquisadores no mundo inteiro estão, essencialmente, no seu rigor metodológico e nas características de seu sistema conceitual aberto e dialético, que permitiram a compreensão aprofundada da natureza e do desenvolvimento dos processos psicológicos humanos. 0 presente artigo centra-se na discussão de aspectos epistemológicos gerais da Teoria Histórico-Cultural de Vygotsky e nas suas implicações para a Psicologia do Desenvolvimento Infantil. Parte-se do debate clássico da Filosofia da Ciência acerca da relação entre sujeito e objeto, que fundamenta a crise da Psicologia referente à escolha do seu objeto de estudo. Em seguida, apresenta-se o Sistema Filosófico Marxista que fornece à Psicologia Histórico-Cultural uma concepção a respeito de mundo e de humanidade, das leis de seu desenvolvimento e das vias de acesso e de produção do conhecimento. Uma vez discutida as bases filosóficas da Teoria Vygotskyana, identificam-se e explicitam-se os seus princípios fundamentais: o princípio da unidade da consciência e da atividade e o princípio da unidade do biológico e do social. Conclui-se com um debate acerca das implicações dessa perspectiva teórico-epistemólogica para a compreensão do desenvolvimento psicológico infantil.
\end{abstract}

Palavras-chave: Psicologia. Epistemologia. Desenvolvimento infantil.

\begin{abstract}
Vygotsky's contributions to research in Psychology seem undeniable today, but remained silenced for some time. The reasons to continue attracting the interest of researchers worldwide are essentially in its methodological rigor and the characteristics of its open and dialectical conceptual system, which allowed in-depth understanding of the nature and development of psychological processes. This article focuses on the discussion of general epistemological aspects of Vygotsky's Historical-Cultural Theory and its implications for the Child Development Psychology. We start with the classic debate of the Philosophy of Science about the relationship between subject and object, which underlies the crisis of psychology regarding the choice of its object of study. Then we present the Marxist Philosophical System that provides to the Historical-Cultural Psychology
\end{abstract}

Psicol. Argum. 2014 jan./mar., 32(76), 161-172 
a conception about world and humankind, the laws of its development and access and production routes of knowledge. Once discussed the philosophical basis of Vygotsky's theory, we identify and explain its fundamental principles: the principle of unity of consciousness and activity and the principle of unity of biological and social. We conclude with a discussion of the implications of this theoretical-epistemological perspective to understand the psychological development of children.

Keywords: Psychology Knowledge Child development. .

\section{Introdução}

Desde que a Psicologia adquiriu o status de ciência independente, a delimitação de seu objeto de estudo tem sido um de seus problemas fundamentais. Sustentada sobre os pilares filosóficos do positivismo, empirismo e materialismo, a Psicologia moderna elegeu um objeto de estudo passível de observação, mensuração e quantificação. Assim, a alma é relegada a objeto de especulação filosófica e a mente, em oposição ao corpo, assume lugar central na sua trama conceitual. Seguindo a tradição cartesiana, assume-se que o corpo seja regido por leis físicas e mecânicas, a exemplo do mundo material a sua volta. A mente, por outro lado, teria sua forma peculiar de organização e funcionamento, que poderia ser compreendida por meio da razão. Inauguram-se, assim, os pólos da objetividade e da subjetividade que norteiam os debates epistemológicos na Psicologia, até os dias atuais.

A busca pela superação dessa dicotomia no corpo teórico da Psicologia permaneceu no campo ideológico e não científico desde o século XIX. Lev Semionovich Vygotsky (1996-1934) é reconhecido mundialmente por ter realizado uma análise rigorosa da situação de fragmentação da psicologia de seu tempo e por ter proposto uma síntese superadora da Crise, lançando mão, para isso, do método materialista dialético de Marx e Engels.

0 tema que será desenvolvido nesse artigo versa sobre alguns aspectos epistemológicos gerais do horizonte teórico-metodológico da Psicologia Histórico-Cultural de Vygotsky e suas implicações para a Psicologia do Desenvolvimento Infantil. Ele está organizado em três partes. Na primeira será reacendido o debate clássico da Filosofia da Ciência acerca da delimitação do objeto de estudo e do modo como abordá-lo, o que remete ao problema da relação entre sujeito e objeto na produção do conhecimento científico (Gutierrez, 2002). Será tomada como base a obra de Vygotsky denominada "O significado histórico da crise na Psicologia", escrita entre 1925 e 1927, mas publicada somente em 1982 (Vygotsky, 1990/1927). Em seguida, será apresentado, em linhas gerais, o Sistema Filosófico Marxista que concede à Psicologia HistóricoCultural uma concepção a respeito de mundo e de homem, das leis de seu desenvolvimento e das vias de acesso e de produção do conhecimento. A partir daí serão elucidados os dois princípios fundamentais dessa abordagem teórico-metodológica: o princípio da unidade da consciência e da atividade e o princípio da unidade do biológico e do social, aplicados à explicação do desenvolvimento ontogenético humano. Finalmente, são apresentadas as implicações dessa perspectiva teórico-epistemológica para a compreensão do desenvolvimento psicológico infantil. Objetiva-se com esse artigo oferecer aos pesquisadores do desenvolvimento humano, em geral, e infantil, em particular, um ponto de partida para auxiliar na definição e discussão metodológica de suas pesquisas.

\section{Crítica metodológica à Psicologia}

A disputa inconciliável entre o objetivismo e o subjetivismo, instaurada na ciência psicológica desde o seu desmembramento da Filosofia, ficou conhecida na década de 20 como a crise da Psicologia. Em seu clássico artigo "O Significado Histórico da Crise da Psicologia", escrito entre 1925 e 1927 e publicado somente em 1982, Vygotsky realiza uma análise extensiva e profunda da Crise e aponta a necessidade de unificação de seu método para que a Psicologia pudesse tornar-se positiva, isto é, ascender a um estado científico de fato.

Em sua análise, Vygotsky (1990/1927) inicia a discussão demonstrando que os conhecimentos psicológicos elaborados na segunda metade do século 
XIX unificaram-se no sistema teórico da Psicologia Mentalista ou Idealista. A Psicologia Idealista ou Mentalista compreende os processos psicológicos de forma relativamente autônoma em relação à base biológica e ao ambiente. Entendido como uma instância psicológica estruturada por imagens e símbolos que não apresentam uma relação lógica e temporal com o contexto social e cultural do indivíduo, o psiquismo seria responsável por gerar seus próprios conteúdos.

Na Psicologia Idealista, o meio de o pesquisador acessar os conteúdos mentais é o racionalista-empírico, que tem como premissa epistemológica a crença de que a capacidade que o sujeito teria de ter consciência dos estados subjetivos poderia ser treinada para fins de produção de conhecimento acerca da própria consciência. A Fenomenologia de Husserl (1859-1938) e o Introspeccionismo de Wundt (1832-1920) são exemplos que representam o idealismo na Psicologia da época.

Nas primeiras décadas do século XX são produzidas profundas críticas contra essa postura metodológica subjetivista, introspectiva e interpretativa. Além do caráter especulativo do método, os mentalistas, de acordo com Vygotsky (1990/1927), ao realizar seus estudos com homens adultos e sãos, assumiam que esse seria o "tipo" de funcionamento psicológico humano que servia de parâmetro para estabelecer o que seriam as "variações" desse "tipo". Partindo de uma visão adultocêntrica e sexista, as crianças e mulheres adultas seriam as "variações". As funções mentais das crianças, por exemplo, eram tomadas como qualitativamente semelhantes às dos adultos, mas quantitativamente inferiores.

Para se contrapor aos idealistas, erguiam-se novos sistemas teóricos em diferentes continentes. As novas correntes teóricas passaram a defender a transformação da Psicologia em uma ciência natural, positiva, a exemplo da Biologia e da Física. Para esse grupo, a Psicologia deveria ser objetiva e materialista, na qual a experiência direta (empiria) seria fundamental na pesquisa científica. Por essa razão, escolas como a Reflexologia de Pavlov (1849-1936) e o Comportamentalismo de Watson eliminaram os fenômenos que não eram diretamente observáveis ou de questionável verificação empírica de seu programa científico. Resultaram de seus empreendimentos experimentais, descobertas parciais que supervalorizavam os fatores orgânicos e ambientais para a compreensão do comportamento humano e que negavam os aspectos subjetivos humanos no campo da pesquisa em Psicologia.

Vygotsky (1990/1927) afirma que os novos sistemas psicológicos acabaram por produzir uma inversão da noção do que era considerado, pela Psicologia Clássica, como "tipo" e "variação". A Reflexologia e o Comportamentalismo, por exemplo, adotaram como "tipo" o animal, ao passo que a "variação" seria o homem. A Psicanálise propõe que a mulher histérica seria o "tipo", enquanto que todos os demais seriam "variações" do funcionamento neurótico. A Psicopatologia segue a mesma direção, propondo variações normais de tipos de caracteres patológicos.

Para o autor, tanto as teorias de base subjetivista como as de base objetivista estavam produzindo conhecimentos parciais, porque empregavam lentes unidimensionais para apreender o objeto. 0 problema epistemológico de base gerava explicações reducionistas da realidade e propagava posturas dogmáticas entre os pesquisadores. O Introspeccionismo, por exemplo, somente interessava-se pela consciência e ignorava a conduta e as manifestações inconscientes. O Comportamentalismo de Watson, por sua vez, apenas reconhecia o comportamento, ignorando a consciência, e a Psicanálise interessava-se, fundamentalmente, pelo conceito de inconsciente em suas múltiplas manifestações. De fato, segundo Vygotsky (1990/1927), cada um desses sistemas buscava construir uma psicologia positiva, atribuindo indiscriminadamente as suas descobertas científicas o status de conceito teórico geral. A Reflexologia, ao estabelecer a noção de reflexo, extrapolava essa noção para explicar toda a conduta animal e humana; a Psicanálise, ao desvendar os impulsos inconscientes, assume-os como princípio da motivação e ato humano.

0 erro metodológico da Psicologia Positivista consistia em empregar somente o enfoque de baixo para cima (que parte do fato empírico, particular e o transforma em conceito científico). 0 autor identifica um padrão uniforme decorrente desse erro: Primeiro se chegava a uma descoberta inicial (reflexo condicionado salivar, neurose histérica, por exemplo). Em seguida, apresentava-se a conceituação e elaborava-se um sistema explicativo (Conduta $\rightarrow$ reflexos; ICS $\rightarrow$ libido). Num terceiro momento, era realizada a generalização do conceito ou sistema explicativo a todas as classes de fenômenos (conduta $\rightarrow$ soma de reflexos; desenvolvimento $\rightarrow$ transformação

Psicol. Argum. 2014 jan./mar., 32(76), 161-172 
da libido). Finalmente, o conhecimento científico desvinculava-se da realidade prática que o havia gerado e era transformado em visão de mundo (ontologia).

Assim, o que Vygotsky sugere é que a fragmentação da Psicologia em escolas e correntes não apenas gerava discordâncias em termos de conclusões a respeito dos fatos psicológicos, mas, sim, que os próprios fatos psicológicos não coincidiam na Ciência Psicológica. Múltiplas abordagens, sobre múltiplos fatos, que geram verdades múltiplas. Nas palavras do autor, "um fato qualquer, expressado sucessivamente mediante os conceitos de cada um desses três sistemas [Introspeccionismo, Reflexologia e Psicanálise], adota três formas completamente distintas; mais exatamente, três aspectos diferentes do mesmo fato; ou ainda melhor, três fatos distintos" (1990/1927, p. 299).

0 autor prossegue deduzindo que o que cada uma dessas escolas pretendia era possuir um sistema explicativo que serviria de base para uma Psicologia Geral. A divergência metodológica gerava, assim, ontologias distintas que eram incomunicáveis entre si e apontava a necessidade prática de se sistematizar uma disciplina metateórica, capaz de reunir um conjunto de conceitos e princípios explicativos comuns para unificar Psicologia.

A falta de princípios teóricos gerais, explicativos, unificadores dentro da Psicologia, levava ao reducionismo, ou ao seu oposto, o ecletismo (González, 2003). Enquanto o enfoque reducionista na Psicologia é movido pelo dogmatismo e orienta-se para o estudo de apenas um aspecto da realidade, a postura eclética aceita e une fragmentos opostos entre si, advindos de distintas teorias e enfoques epistemológicos, sem preocupar-se em realizar uma análise concreta que leve em consideração as relações, o lugar e o momento em que uma determinada afirmação é verdadeira e a contrária não o é.

Para Vygotsky (1990/1927), as respostas produzidas para superar a crise: negar a crise, oferecida pelo ecletismo, ou tomar um partido entre posições polarizadas e reducionistas (minha teoria versus as teorias erradas), não haviam sido satisfatórias. $\mathrm{Na}$ sua visão, ambos os posicionamentos desconsideravam a essência dialética e histórica dos fenômenos psicológicos e sociais. Vygotsky (1990/1927) opta pelo método positivo, explicativo e científico, mas expressa suas reservas. Para ele a Psicologia, além de materialista e científica, deveria ser dialética e histórica. A postura dialética busca descobrir a unidade real e o caráter concreto e multidimensional dos fatos e o historicismo é considerado um aspecto essencial na explicação dos fatos e fenômenos do desenvolvimento do homem como ser social.

\section{Sistema Filosófico do Materialismo Histórico e Dialético}

De um ponto de vista materialista histórico e dialético, o mundo natural, físico - das coisas - é distinto do mundo social e histórico dos homens. Ainda que todos os fenômenos da realidade mantenham uma relação de interdependência (ou de relação mútua entre si), as leis que regem as relações de dependência entre os objetos do mundo físico são naturais, frutos de investigação de diferentes ramos das ciências naturais, como a física e a química (Marx \& Engels, 2002/1845).

Os fenômenos de natureza histórico-social, por sua vez, têm leis próprias inerentes a essa natureza. Nessa perspectiva filosófica, as leis das ciências naturais não dariam conta da elucidação dos problemas humanos. Para Vygotsky (1990/1927), o método materialista dialético seria o único método capaz de oferecer as leis gerais que buscam compreender e explicar os fenômenos psicossociais.

As leis do materialismo dialético baseiam-se na lógica dialética hegeliana, substituída a sua base idealista por uma perspectiva material da realidade. A dialética hegeliana é dita idealista porque exclui elementos históricos e materiais de sua análise da realidade (Marx \& Engels, 2002/1845). Para Marx e Engels (2002/1845) a dialética idealista de Hegel produz uma história de natureza mnemônica, isto é, que se fundamenta na consciência da consciência. De acordo com a visão marxista, o erro da dialética hegeliana está em pressupor que a consciência explica o ser, quando em realidade deveria ser o ser social, em suas condições concretas de vida, que determinaria a consciência. Assim, enquanto que para Hegel o mundo se constitui a partir do pensamento, para Marx e Engels (2002/1845) o pensamento é que se constitui a partir da realidade, pois "as idéias nada mais são do que coisas materiais transpostas e traduzidas na cabeça dos homens" (p. 203).

A partir dessa perspectiva, o mundo não é visto como um conjunto de coisas perfeitas e acabadas, mas sim como um complexo de processos. As 
fases do processo são a tese, antítese e síntese. 0 confronto da tese com a antítese gera uma síntese, qualitativamente diferentes do estágio anterior de desenvolvimento. 0 desenvolvimento dos processos não segue um movimento linear e é necessário captar seu movimento e as forças que promovem os saltos.

Todo fenômeno psicológico, nesse sentido, somente pode ser compreendido em sua dinamicidade, dentro das condições sociais e históricas em que é produzido. Compreender o fenômeno psicológico e social implica desvendar sua estrutura e processo, situá-lo no espaço e tempo. Qualquer investigação que toma o homem fora de seu contexto histórico leva ao conhecimento parcial e ideologizado (Marx \& Engels, 2002/1845). Assim, a visão de mundo e de ser (ontologia) do materialismo histórico e dialético implica um olhar e uma compreensão do mundo (epistemologia) e de homem (antropologia).

Além disso, o método dialético se expressaria concretamente na integração de diferentes técnicas e práticas profissionais da Psicologia que estavam se desenvolvendo desconectadas da psicologia teórica. Para Vygotsky (1990/1927), a prática teria um papel fundamental no desenvolvimento da ciência psicológica. De fato, ao confrontar-se com os problemas práticos observados na clínica, na escola e na indústria, a Psicologia se veria obrigada a rever seus próprios princípios. $\mathrm{O}$ autor conclui, com base nesse raciocínio, que a epistemologia e a prática formam uma unidade que dá origem e impulsiona a Crise e, em si mesma, a fonte de sua superação.

\section{Teoria histórico-cultural}

A Teoria histórico-cultural de Vygotsky nasceu como um projeto científico ambicioso que buscava construir uma Psicologia verdadeiramente científica, assentada sob o método materialista histórico e dialético. De fato esse foi um projeto inédito, ainda que na Rússia pós-revolução (1917) toda a Psicologia de linha marxista estivesse empenhada em construir uma Psicologia positiva. Isso porque o momento histórico pós-revolucionário imprimia uma nova organização social na Rússia, que visava instaurar o comunismo como modo de produção. Com a Revolução Socialista, uma série de demandas foram impostas às diferentes áreas de conhecimento. Como resposta a essas demandas, surgiam tentativas de construir uma Biologia Marxista, uma Física Marxista, uma Ciência Agrícola Marxista (Kozulin, 1994; Rubinstein, 1964).

Vygotsky (1990/1927) afirmava que a Psicologia Marxista podia ser tão dogmática, reducionista e falsedora da realidade quanto qualquer outra corrente na Psicologia. No seu texto "Sobre Método de Investigação Reflexológica em Psicologia" (Vygotsky, 1984/1930) o autor analisa os trabalhos de alguns pesquisadores russos da época como Blonski (1884-1941), Kornilov (1879-1957), Bekhterev(1857-1927) e Pavlov (1849-1927) que aboliram a consciência e processos psicológicos superiores e mostra-se contrário a essa postura dogmática: "Não quero descobrir [a natureza da] psique de graça, recolhendo algumas citações. Quero aprender, a partir do conjunto do método de Marx como construir uma ciência, como abordar a investigação da psique" (Vygotsky, 1991/1925, p. 421).

No artigo "A Consciência como Problema da Psicologia do Comportamento" (1991/1925), contrapondo-se ao pensamento hegemônico mecanicista, Vygotsky defende a ideia de que a Psicologia como ciência particular deveria dirigir seus esforços à pesquisa da consciência e da conduta do homem, como ser histórico, social, trabalhador e consciente. 0 autor partia da premissa de que os fenômenos psicológicos tipicamente humanos, aqueles mediados pelos signos, como a atenção voluntária, a memória episódica e semântica e o pensamento verbal, seriam qualitativamente diferentes dos processos psicológicos elementares, observados numa variedade de espécies animais. Orientado pela ideias de Marx, Vygotsky apontava que o método "de cima para baixo" poderia ser útil na Psicologia, assim como fora na análise econômica e social da sociedade capitalista produzida em "O Capital".

\section{0 desenvolvimento dos processos psicológicos superiores}

Os processos psicológicos superiores dizem respeito às capacidades psicológicas especificamente humanas, como o pensamento conceitual, a memória semântica e a imaginação que se formam pela mediação cultural e se desenvolvem com a ajuda dos procedimentos sociais de produção intelectual, dos quais se apropria o indivíduo. Consequentemente, sua estrutura e o mecanismo de sua realização têm

Psicol. Argum. 2014 jan./mar., 32(76), 161-172 
uma origem social e se desenvolvem sob a influência da educação informal e formal na maioria das culturas humanas (Vygotsky, 1995/1931).

Os processos psicológicos elementares, por sua vez, presentes também em outras espécies animais, deveriam ser explicados mediante a complexificação de estruturas e do funcionamento de seu sistema nervoso, pela ação das leis biológicas da evolução propostas por Darwin (1859). Entretanto, para explicar o psiquismo humano, o autor enfatizava que as leis da evolução biológica deveriam ceder lugar à ação das leis de natureza histórico-social (Vygotsky \& Luria, 1996; Vygotsky, 1995/1931). Para o autor, na realidade, as duas linhas de desenvolvimento (a natural e a histórico-cultural) estão presentes na ontogênese formando um processo único e complexo que se interpenetram, dando origem a um indivíduo de natureza biológico-social.

Essa diferenciação entre as linhas de desenvolvimento foi posteriormente alvo de críticas de seus seguidores, como Davidov, que a entendia como desnecessária, haja vista que as funções psicológicas do ser humano, desde seu nascimento, são socialmente determinadas (Davidov, 1988). Leontiev e Luria (1968) defenderam, entretanto, que tal divisão dos processos em linhas de desenvolvimento constituía somente um artifício metodológico. Nas palavras de Vygotsky (1987, p. 40):

El desarrollo cultural del niño se caracteriza precisamente, en primer lugar porque se realiza con un cambio dinámico del tipo orgánico. Se apoya sobre los procesos de crecimiento, maduración y progreso orgánico del niño y forma con él un todo único. Solamente mediante la abstracción podemos separar estos procesos.

Como é possível deduzir, dentro da lógica materialista histórica e dialética, a análise do psiquismo deveria partir daquelas formas da conduta que diferenciam a conduta do homem da conduta dos demais animais. Nos animais, o processo que envolve as relações de regulação entre o organismo e seu meio fundamenta-se tanto nas mudanças adaptativas que acontecem no organismo (e órgãos) como no psiquismo; desde sua forma mais elementar, encontrada em seres vivos bastante simples, até as formas mais complexas, encontradas em símios e, em grande extensão, no homo sapiens (Leontiev, 1978b).
Diferentemente dos demais animais, é peculiar ao homem a capacidade de intervir transformando radicalmente o meio em que vive. Ao transformar a realidade, o homem transforma a si mesmo (Leontiev, 1978b). Os meios e os processos envolvidos na transformação da natureza são, ao mesmo tempo, objetivos (instrumentos externos) e subjetivos (instrumentos internos, ou psicológicos). A atividade é a categoria que explicita a dialética do sujeito e objeto. Assim, a relação do homem com a realidade que o rodeia é definida como uma inter-relação ativa (Rubinstein, 1962; Kossakowski, 1987; Leontiev, 1978a).

Essa visão sustenta um dos mais importantes princípios da Psicologia Vygotskyana: o princípio da unidade da consciência e da atividade. Aqui a consciência adquire materialidade/objetividade e sai do campo da metafísica, deixando de ser uma entidade abstrata (Kossakowski, 1987; AbuljanovaSlavskaia, 1987; Colectivo de Autores, 1989).

\section{Princípio da unidade da consciência e da atividade}

O princípio da unidade da consciência e da atividade explicita o caráter dialético e materialista dessa abordagem. A categoria atividade foi desenvolvida inicialmente por Rubinstein e Leontiev, a partir da década de 1930 (Rubinstein, 1962, 1964). Enquanto Leontiev tomou como objeto central da Psicologia a atividade externa, prática do sujeito, Rubinstein centrava seus esforços para elucidar o problema da atividade interna da personalidade.

Para Leontiev (1978a) a atividade tipicamente humana é movida por necessidades ou interesses de um sujeito para uma finalidade. 0 sujeito é ativo e atua sobre os objetos da realidade, mas a sua atuação não é biologicamente programada, mas sim impulsionada por motivos. A atividade humana é, por isso, sempre orientada para algo ou alguém, como um movimento resultante das necessidades (ou interesses) internas e externas dos sujeitos.

Rubinstein (1962), por sua vez, enfatizou a importância central da categoria personalidade para a teoria psicológica de orientação filosófica marxista. Para o autor, o psiquismo humano surge e se manifesta na atividade externa (na transformação do mundo e de si mesmo), como um reflexo do mundo social e natural que existe fora do sujeito. Entretanto, a consciência humana e a personalidade têm um papel ativo e criador na atividade humana 
de transformação do mundo e de si mesma. Esse papel pode ser percebido na regulação intencional de toda atividade externa (falar, ler, andar etc.).

Pesquisadores atuais dessa escola teórica entendem que a abordagem das diversas funções psíquicas superiores, a partir da categoria atividade, necessita considerar suas duas características fundamentais: sua objetividade e sua subjetividade (González, 2003). A atividade não só é objetiva no sentido de que está determinada pelo mundo material objetivo, mas também no sentido de que o mundo material atua sobre o homem por meio de sua atividade e não diretamente. Surge, assim, uma interação recíproca entre o objeto e o sujeito da atividade: por um lado, o objeto aparece em uma relação com a atividade e, por outro, o sujeito se dirige ao objeto como objeto de uma necessidade (Gutierrez, 2002).

\section{A unidade do biológico e do social}

O segundo princípio fundamental da teoria histórica é o princípio da unidade entre o biológico e o social. A relação entre a biologia e a cultura é um tema historicamente controverso na história da Psicologia, revelando posicionamentos irredutíveis e inconciliáveis. Segundo Zaporozhets (1987), a oposição do biológico e do social deve ser considerada como relativa, haja vista que as particularidades morfofisiológicas do homem se desenvolveram e fixaram hereditariamente no período da antropogênese primitiva, sob a influência das práticas socioprodutivas do homem na sociedade primitiva e, também, de sua comunicação linguística.

A visão de Zaporozhets (1987) é representativa da Psicologia Histórico-Cultural que enfatiza a dependência da consciência humana nas condições educativas e vitais da sociedade, mas não nega as propriedades orgânicas do indivíduo para seu desenvolvimento psicológico (Luria, 1978). Um ser vivo tem que nascer com particularidades morfofuncionais herdadas, especificamente humanas, para que possa produzir-se um processo de desenvolvimento psíquico especificamente humano (Luria, 1978).

Experimentos realizados com primatas (Kellogg \& Kellogg, 1933; Ladygina-Kohts, 2002 e Gardner \& Gardner, 1994) constatam que se eles são colocados em condições de vida e educação similares as de uma criança, adquirem uma série de comportamentos não usuais para sua espécie, mas, apesar disso, não alcançam as qualidades psíquicas características dos homens. Essas constatações corroboram a hipótese de que sejam necessárias características genéticas e funcionais de um cérebro humano para que seja possível o processo específico da ontogênese do psiquismo humano (Zaporozhets, 1987).

As diferenças qualitativas entre os animas e humanos, sustentadas pelas bases orgânicas, também podem ser observadas entre o desenvolvimento ontogenético e o desenvolvimento filogenético do psiquismo humano (Vygotsky, 1991/1925). Enquanto a filogênese da consciência humana se desenvolve sem mudanças relevantes nas propriedades morfológicas do homem da transição do paleolítico médio para o superior (Vygotsky, 1991/1925; Mithen, 1998), a ontogênese do psiquismo na criança ocorre no processo de amadurecimento de um organismo infantil (Vygotsky, 1995/1931; Luria, 1978). Assim, o cérebro de um recém-nascido se diferencia do cérebro adulto quanto ao seu tamanho e à sua estrutura interna, assim como quanto às suas possibilidades funcionais (Luria, 1988). Antes de atingir seu amadurecimento, experimenta mudanças essenciais e, nos diferentes períodos de desenvolvimento, geram-se possibilidades diferenciadas para a apropriação de novas experiências e formação de novos processos (Vygotsky, 1995/1931; Luria, 1988). A esse respeito, existe a hipótese de que a aprendizagem, que estimula o desenvolvimento de determinadas funções psicofisiológicas, seja particularmente efetiva nos primeiros anos de vida, quando acontecem os períodos mais intensos de amadurecimento dos mecanismos nervosos correspondentes (Vygotsky, 1995/1931; Luria, 1988). A partir dessa perspectiva teórica, a aprendizagem não só conduziria a mudanças funcionais, mas poderia ter também influência direta na formação do substrato cerebral da atividade psíquica. Em contrapartida, as particularidades morfofisiológicas, como um processo de amadurecimento normal na infância, são condições não só importantes, mas necessárias, para um desenvolvimento psicológico satisfatório.

\section{0 desenvolvimento infantil sob o ponto de vista da Psicologia Histórico-Cultural na atualidade: Implicações para a pesquisa}

A psicologia Vygotskyana atual aborda o desenvolvimento psicológico como um processo dinâmico

Psicol. Argum. 2014 jan./mar., 32(76), 161-172 
que conduz a mudanças quantitativas e qualitativas do conjunto de funções e atividades, assim como dos elementos particulares do comportamento humano (Galperin, 1987; Davidov, 1988; Colectivo de Autores, 1989; Przetacznikowa, 1987). A mudança no desenvolvimento psicológico tem caráter progressivo e orientado à realização de formas cada vez mais efetivas de regulação da inter-relação entre o indivíduo e o meio (Zaporozhets, 1987; Galperin, 1987; Davidov, 1988; Colectivo de Autores, 1989; Przetacznicowa, 1987).

As mudanças qualitativas, mais importantes, ou seja, as transformações essenciais na conduta dos indivíduos e na sua consciência, determinam o passo à fase seguinte de desenvolvimento, a uma nova fase da vida, diferenciada das precedentes. Parte-se de uma concepção de desenvolvimento por estágios, por sequência de fases (Leontiev, 1978b; Vygotsky, 1995/1931; Zaporozhets, 1987). Os períodos ou etapas e dentro deles as fases, delimitadas por mudanças específicas de menor abrangência, constituem fatos psicológicos reais. Em outras palavras, essa característica de constituição em etapas (a regularidade da sucessão das mudanças no desenvolvimento) é considerada uma propriedade estrutural do processo de desenvolvimento e, ao mesmo tempo, um elemento essencial da organização psíquica (Leontiev, 1978b; Vygotsky, 1995/1931; Zaporozhets, 1987).

Naturalmente, os limites dos estágios não são fixos e dependem da dinâmica e do ritmo individual de desenvolvimento. Mas, em cada etapa surge um complexo peculiar de qualidades que em cada criança se manifesta de maneira individual e única. A delimitação e aproximação dos estágios a respeito de determinados anos da vida (delimitação cronológica) tem lugar sobre a base de três critérios: 1) 0 tipo e o nível de conhecimento e consciência da realidade que circunda a criança; 2) A atividade predominante na criança; 3) As formas e métodos específicos de influência educacional (Leontiev, 1978b; Zaporozhets, 1987).

0 primeiro critério significa que em cada um dos períodos mencionados se verificam mudanças essenciais no tipo de compreensão dos objetos e fenômenos do mundo circundante, mudanças no tipo de conhecimento da realidade (nas formas da percepção, memória, pensamento etc.). 0 segundo critério assinala que em cada período ocorrem importantes mudanças na atividade da criança, mostrando novas formas de ação e de atividades que modificam sua conduta. Com o terceiro critério se explicita que cada período exige suas próprias formas e métodos de influência educativa sobre a criança. Com a influência constante do meio educacional e com a idade, muda o volume e o caráter das informações que estimulam o desenvolvimento dos conhecimentos e se diferenciam os meios de educação de crianças e jovens (Zaporozhets, 1987). Vale ressaltar que os três critérios mencionados são abordados na sua relação mútua: as mudanças na consciência se realizam sob a influência da educação e se expressam nas mudanças de atividade e ação da criança.

\section{Sobre a análise condicional e causal do desenvolvimento}

Para Przetacznikowa (1987), o problema das condições e dos fatores do desenvolvimento psíquico é ao mesmo tempo o problema de seus mecanismos, das forças motrizes de sua dinâmica. A análise condicional e causal do desenvolvimento ontogenético pode contribuir à solução do problema (Przetacznikowa, 1987). A primeira (a análise condicional) procura a pesquisa das condições nas quais se realiza o desenvolvimento do homem; a outra (a análise causal) procura identificar e explicar os nexos entre causas e efeitos neste processo.

Ao diferenciar as condições das causas, a autora propõe que o desenvolvimento psicofísico de um organismo é um processo que se efetua em determinadas condições. Das condições de desenvolvimento depende a aparição e continuidade de um determinado fenômeno, ou a permanência de um estado de coisas. As causas, por sua vez, são um tipo particular de condições. Entretanto, elas somente podem ser identificadas quando um determinado fenômeno ocorre, necessariamente, a partir de outro, numa relação irreversível (Przetacznikowa, 1987).

Frequentemente, na Psicologia do Desenvolvimento, tanto as condições externas (meio) como as internas do desenvolvimento psicológico (fatores orgânicos) são chamadas fatores de desenvolvimento. As causas, nesse contexto, são ao mesmo tempo os mecanismos e as forças motrizes do desenvolvimento, sendo que as forças motrizes estão inter-relacionadas por uma rede de causas e efeitos com as mudanças e efeitos evolutivos.

A partir da análise condicional e causal proposta por Przetacznikowa (1987), é estabelecida uma abordagem alternativa que estabelece uma 
delimitação entre as condições em que acontece o desenvolvimento psicológico e as determinantes, ou causas, do dito desenvolvimento. No grupo dos condicionantes, encontramos as condições genéticas e ecológicas do desenvolvimento psicológico, que correspondem aos fatores tradicionalmente chamados de "orgânicos" e "meio" na psicologia do desenvolvimento. No segundo grupo, das causas, estão a "atividade" e a "educação", ou seja, aqueles fatores que influenciam diretamente nas mudanças evolutivas.

Dentre as condições orgânicas, destacam-se aquelas relacionadas com a dotação genética do indivíduo, com seu genótipo. Como estabelece a genética atual, os chamados modos de desenvolvimento dependem de diferenças genotípicas, e os fatores genéticos aportam predisposições para o desenvolvimento individual (Wolanski, 1970; Alexander, 1989; Keller, 2002). A influência dos genes sobre as características psicológicas é mediada e não mecânica e, portanto, muda em dependência de diversas condições relacionadas ao ambiente. Da mesma forma, a influência do meio sobre as características psicológicas depende das condições herdadas dos indivíduos. Para Przetacznikowa (1987) os fatores ecológicos, tais como a pertença a uma determinada classe social, a situação econômica da família, a formação e profissão dos pais e outras, funcionam de modo distinto em diversas culturas e, por essa razão, o alcance de sua influência não pode ser determinada de modo geral.

$\mathrm{Na}$ explicação das causas, Przetacznikowa (1987) considera os fatores necessários e imprescindíveis no desenvolvimento dos processos psíquicos e das formas de ação do indivíduo. Na análise causal dinâmica dos determinantes do desenvolvimento que influenciam as diversas etapas da ontogênese, podem ser determinados os mecanismos de alguns fenômenos que se expressam em mudanças e características do desenvolvimento psicológico. Entre os determinantes mais importantes do desenvolvimento infantil, a autora destaca a atividade, indispensável para o desenvolvimento e a educação que dirige o desenvolvimento da consciência e da personalidade da criança mediante mecanismos supraordenados de regulação e adaptação.

Assim, a análise condicional do desenvolvimento apresentada tem por objetivo identificar e explicar o conjunto de condições externas e internas onde se produz o desenvolvimento psicológico da criança, enquanto a análise causal tenta dar resposta, primariamente, por que ou de que modo e por que meio acontecem as mudanças evolutivas.

\section{Sobre o papel da atividade da criança}

A atividade da criança possui uma qualidade particular: é uma determinante do seu desenvolvimento psíquico e, ao mesmo tempo, está sujeita a ela mesma, na medida em que avança a idade, ao desenvolvimento e ao aperfeiçoamento (Leontiev, 1978b; Zaporozhets, 1987). 0 caráter progressivo da atividade humana consiste, precisamente, no fato de que no curso de vida se diversificam e ampliam seus campos de ação, as diversas ocupações se aperfeiçoam e, além disso, devido ao fato de que o homem, em um meio cada vez mais complexo, mudar o repertório de suas atividades e ações, possibilita-se uma regulação eficiente de suas relações com o meio (Leontiev, 1978b; Zaporozhets, 1987). Finalmente, vale ressaltar que a plasticidade da atividade própria dos humanos, que implica a capacidade de desenvolver novas formas de atividades e ações, transformar as já desenvolvidas, ou dar-lhes outra direção, é inversamente proporcional à idade do indivíduo; ou seja, maior na infância e na juventude que nas etapas posteriores do desenvolvimento (Leontiev, 1978a; Zaporozhets, 1987).

\section{Sobre o papel da educação}

A formação do psiquismo na ontogênese não se apoia somente nos contatos casuais da criança com os diversos elementos do meio, numa interação acidental entre o indivíduo, os acontecimentos e fenômenos que são um produto da vida social. A interação social é conduzida de forma consequente pelos educadores da criança e pelas diversas instituições sociais que se ocupam especialmente da organização e execução do processo de educação e prestam ajuda aos pais no desempenho das funções educativas (Vygotsky, 1994). 0 meio educacional, seja na família, na pré-escola, na escola etc., pode ser considerado como um elemento das condições de vida da criança no sentido amplo, ou seja, dos fatores ecológicos do desenvolvimento (Vygotsky, 1994; Zaporozhets, 1987).

Por outro lado, os processos de educação que têm lugar nesse meio constituem, junto à

Psicol. Argum. 2014 jan./mar., 32(76), 161-172 
atividade, o segundo determinante indispensável do desenvolvimento ontogenético (Vygotsky, 1994; Zaporozhets, 1987). A essência desse processo consiste em produzir, na psique da criança em desenvolvimento, mudanças relativamente permanentes por meio das influências educativas, aquelas que têm sentido progressivo, ou seja, contribuem com o desenvolvimento social e individual da pessoa e correspondem a objetivos educacionais e sociais. Dependendo do tipo de educação, as influências terão um caráter mais ou menos intencional, consciente, planificado e organizado (Galperin, 1959).

Essa visão tem implicações para a análise psicológica da prática educativa atual, na qual os objetivos, os métodos e os meios de educação estão habitualmente adaptados às idades das crianças e suas etapas de desenvolvimento, assim como às qualidades individuais da pessoa em desenvolvimento. De acordo com a perspectiva Vygotskyana, as exigências educacionais devem superar o nível atual de desenvolvimento psíquico do indivíduo. A educação só é efetiva - afirmava Vygotsky (1994), quando se antecipa ao desenvolvimento e se dirige àquelas qualidades que se encontram ainda nos seus rudimentos, que não estão ainda amadurecidas.

A força da educação como determinante do desenvolvimento está, sobretudo, no fato de que ela é um processo social. Ela se configura como um processo organizado e executado por toda a sociedade. Diferentes instituições da vida social se implicam na realização e nos efeitos e resultados deste processo, desde a família e a comunidade, até amplos círculos da sociedade; todos eles participam de forma mais ou menos direta na educação das novas gerações. Ambos, os determinantes do desenvolvimento-educação e a atividade própria, estão intimamente vinculados. A educação que a sociedade e os outros proporcionam se transforma, progressivamente, durante o desenvolvimento individual, em autoeducação e autoformação, existindo entre ambos os fatores uma estreita interdependência.

\section{Consideracões finais}

A compreensão das bases filosóficas e epistemológicas de um determinado aporte teórico faz-se premente quando ingressamos no campo da pesquisa em Psicologia. 0 problema da delimitação do objeto de estudo tem sido abordado pelas diferentes disciplinas científicas e constitui o método de uma ciência particular. Falar de método, portanto, implica abordar o processo de produção de conhecimento desde um ponto de vista filosófico, explicitando uma concepção de mundo e do ser (ontologia), uma teoria geral acerca do modo como conhecê-los (epistemologia) o que necessariamente depende do estabelecimento da relação entre o objeto e o sujeito, e uma visão sistematizada das vias e dos meios (instrumentos e procedimentos, ou da tecnologia) para acessar e/intervir sobre o objeto de estudo (metodologia).

No âmbito das ciências humanas, interessa uma classe particular de fenômenos - os fenômenos psicossociais. 0 homem, em suas mais variadas atividades no mundo (atividades nas quais estabelece relação com os objetos do mundo, com outros homens e consigo mesmo) é o objeto de estudo das ciências humanas. Por essa razão, de um ponto de vista metodológico, interessa também ao pesquisador explicitar a sua antropologia, ou, dito de outra forma, a visão de homem da qual parte para explicar os fenômenos humanos.

Diferentemente dos fenômenos naturais, os fenômenos de natureza psicossocial são objetos de difícil delimitação e apreensão. A dificuldade deve-se a dois fatores essenciais: de um lado, à própria natureza complexa, processual e multidimensional dos fenômenos psicossociais; de outro, aos meios disponíveis para acessá-los e compreendê-los. Acessamos e desvendamos a realidade humana por meio das capacidades humanas do pensamento, como a de raciocinar, analisar, abstrair, sintetizar e generalizar. A discussão do método é, portanto, de natureza filosófica, e fundamenta o processo de produção de conhecimento, nas mais diversas áreas do conhecimento, mas tem relevância particular para as ciências humanas. Daí a necessidade de promover debates dessa natureza no contexto de formação de pesquisadores e professores universitários brasileiros.

\section{Referências}

Abuljanova-Slavskaia, K. A. (1987). Personalidad y actividad. In Coletivos de autores. Psicología en el Socialismo (pp 174-180). Habana: Ed. Ciencias Sociales. 
Alexander, R. D. (1989). Evolution of the human psyche. In P. Mellars, \& C. Stringer (Eds.). The human revolution: Behavioural and biological perspectives on the origins of modern humans (pp. 455-513). Edinburgh: Edinburgh University Press.

Colectivo de Autores (1989). Temas sobre la Actividad y la Comunicación. Habana: Ed. Ciencias Sociales.

Darwin, C. (1859). The origin of species. London: Murray.

Davidov, V. (1988). La enseñanza escolar y el desarrollo psíquico. Moscú: Progreso.

Galperin, P. I. (1987). Sobre la investigación del desarrollo intelectual del niño. In M. Shuare, \& Davidov, V. (Orgs.). La psicología evolutiva y pedagógica en la URSS (pp. 125-143), Moscú: Editorial: Progreso.

Galperin, P. (1959). Desarollo de las investigaciones sobre la formación de las acciones mentales. In La Ciencias Psicologica en la URSS (Vol. 1, pp. 446-463). Moscú: Academia de Ciencias Pedagogicas de La RSFSR.

Gardner, B. T., \& Gardner, R. A. (1994). Development of phrases in the utterances of children and cross-fostered chimpanzees. In Gardner, R.A., Gardner, B.T., Chiarelli, B., \& Plooij, F.X. (Eds.). The ethological roots of culture (pp. 223-255). Dordrecht: Kluwer Academic Press.

González, D. J. (2003). La unidad y la diversidad de la teoría psicológica. Revista Cubana de Psicologia, 20(2), 173-188.

Gutierrez, A. C. (2002). O problema científico: construção formal ou delimitação no real. Tese de Doutorado, Centro de Ciências da Educação, Universidade Federal de Santa Catarina, Florianópolis.

Keller, H. (2002). Development as the interface between biology and culture: a conceptualization of early ontogenetic experiences. In H. Keller, Y. H. Poortinga, \& A. Schölmerich. (Orgs.). Between biology and culture: Perspectives on ontogenetic development (pp. 159190). Cambridge: Cambridge University Press.

Kellogg, W. N., \& Kellogg, L. A. (1933). The ape and the child: A study of environmental influence upon early behavior. Nova York: Mcgraw Hill Book Co.
Kossakowski, A. (1987). Acerca de la actividad de orientación para la acción independiente de la personalidad. In Coletivos de autores. Psicologia en el Socialismo (pp. 98-112). Habana: Ed. Ciencias Sociales.

Kozulin, A. (1994). La psicologia de Vygotsky. Madrid: Alianza Editorial.

Ladygina-Kohts, N. N. (2002). Infant chimpanzee and human child: A classic 1935 comparative study of ape emotions and intelligence (Frans, B. M., Ed.; Vekker, B., Trad.). Oxford University Press.

Leontiev, A. (1978a). Actividad, conciencia y personalidad. Buenos Aires: Ciencias del Hombre.

Leontiev, A. (1978b). O Desenvolvimento do Psiquismo. Lisboa: Livros Horizonte.

Leontiev, A.N. \& Luria, A.R. (1968). The Psychological Ideas of L.S.Vygotskii. Em B.B.Wolman (Org.), Historical Roots of Contemporary Psychology. New York: Harper \& Row.

Luria, A. R. (1978). El cerebro en acción. Ciudad de la Habana: Editorial Pueblo y Educación.

Luria, A. R. (1988). 0 cérebro humano e a atividade consciente. In Vygotsky, L. S., Luria, A. R., \& Leontiev, A. N. Linguagem, desenvolvimento e aprendizagem. São Paulo: Edusp.

Marx, K., \& Engels, F. (2002). A ideologia alemã. São Paulo: Martins Fontes.

Mithen, S. (1998). A pré-história da mente: uma busca das origens da arte, da religião e da ciência (Oliveira, L. C. B. de, Trad.). São Paulo: Editora da UNESP.

Przetacznikowa, M. (1987). Condiciones y determinantes del desarrollo psíquico. In Coletivos de autores. In Psicología en el Socialismo (pp. 269-278). Habana: Ed. Ciencias Sociales.

Rubinstein, S. L. (1962). Existenta si Constiinta. Bucuresti: Ed. Stiintificã.

Rubinstein, S. L. (1964). El desarrollo de la psicologia: Principios y métodos. Habana: Editorial Nacional de Cuba.

Psicol. Argum. 2014 jan./mar., 32(76), 161-172 
Vygotsky, L. S. (1990). El significado histórico de la crisis de la psicología. In Obras escogidas (Vol. 1, pp. 257 407). Madrid: Visor.

Vygotsky, L. S. (1984). El método de investigación reflexológica y psicológica. Infancia y aprendizaje, 27/28, 87-104.

Vygotsky, L. S. (1987). Historia del desarrollo de las funciones psíquicas superiores. Habana: Editorial Científico Técnica.

Vygotsky, L. S. (1991). A consciência como problema da psicologia do comportamento. In Obras escogidas (Vol. 1, pp.257-407). Madrid: Visor.
Vygotsky, L. S. (1995). Historia del desarollo de las funciones psíquicas superiores. In Obras escogidas. Madrid: Visor.

Vygotsky, L. S. (1994). A formação social da mente (5 ed.). São Paulo: Martins Fontes.

Wolanski, N. (1970). Genetic and ecological factors in human growth. Human Biology, 42, 249-368.

Zaporozhets, A. V. (1987). El papel de lo biológico y lo social en la ontogénesis de la psiquis humana. In Coletivos de autores. Psicologia en el Socialismo (pp. 262-269). Habana: Ed. Ciencias Sociales. 